\title{
Percepção e práticas sobre a raiva da população atendida nos serviços primários de saúde
}

\author{
Perception and practices about rabie of the population \\ carred for in primary health services
}

\author{
Vinicius de Lima Lovadini' • Laura Luisa Gonçalves Lorena ${ }^{2}$ \\ Jaqueline da Silva Lacerda ${ }^{3}$ Márcia Marinho ${ }^{4}$
}

\begin{abstract}
RESUMO
Introdução: A raiva é uma encefalite viral aguda, transmitida por mamíferos com letalidade próxima de $100 \%$, acarretando graves problemas econômicos e na saúde pública, principalmente em países em desenvolvimento e subdesenvolvidos. Enfermidade causada por vírus do gênero Lyssavirus, pertencente à família Rhabdoviridae, que se espalha pelo sistema nervoso central e encontra-se em sobressalentes concentrações nas glândulas salivares de seu reservatório. Objetivo:Avaliar o conhecimento da população usuária das Unidades Básicas de Saúde em relação à Raiva no município de Birigui, estado de São Paulo. Material e Métodos: Utilizou-se um questionário com questões fechadas a fim de identificar e categorizar o conhecimento e atitudes da população frente à Raiva. Foram entrevistados 400 pacientes de ambos os sexos, escolhidos de forma randômica. Resultados: $74,25 \%$ dos entrevistados eram do sexo feminino, sendo $44 \%$ alocados na faixa-etária entre 31 a 50 anos, $45,25 \%$ possuíam o ensino médio completo, $97,25 \%$ já tinham ouvido falar sobre a Raiva, $67 \%$ sabiam quais eram os transmissores da enfermidade e $85,05 \%$ adotavam esquema imunoprofilático contra a Raiva em seus animais. Conclusão: A população demonstrou conhecimento elevado sobre a Raiva, visto que em sua maior parte os entrevistados souberam quais eram os fatores causadores da doença como a transmissão, letalidade, terapêutica e medidas de prevenção, além de já terem ouvido falar sobre a zoonose em sua maior parte por meios digitais ou trocas de informações entre os indivíduos.

Palavras-chave: Lyssavirus; Saúde pública; Epidemiologia; Inquéritos e questionários, Pesquisa sobre serviços de saúde.
\end{abstract}

\begin{abstract}
Introduction: Rabies is an acute viral encephalitis, transmitted by mammals with almost $100 \%$ of lethality, causing serious economic and public health problem, especially in developing and underdeveloped countries.A disease caused by a virus of the genus Lyssavirus, belonging to the Rhabdoviridae family, which spreads through the central nervous system and is found in isolated concentrations in the salivary glands of its reservoir. Objective: To evaluate the knowledge of the user population of the Basic Health Units in relation to rabies in the city of Birigui, state of São Paulo. Material and Methods: A questionnaire with closed questions was used to identify and categorize the population's knowledge and attitudes towards rabies. Four hundred randomly selected patients of both sexes were interviewed. Results: $74.25 \%$ of respondents were female, with $44 \%$ allocated between $3 \mathrm{I}$ and 50 years old, $45.25 \%$ completed high school, $97.25 \%$ heard about rabies, $67 \% \mathrm{knew}$ which disease transmitters and $85.05 \%$ adopted the rabies immunoprophylactic regimen in their animals. Conclusion:The population had a high knowledge of rabies, since most respondents knew what were the factors that caused the disease, such as transmission, lethality, therapy and prevention measures, and have heard about zoonosis by itself. mainly by digital means or exchanges of information between individuals.
\end{abstract}

Key words: Lyssavirus; Public health; Epidemiology; Inquiry and questionnaires; Health Services Research. 


\section{INTRODUÇÃO}

A raiva é uma encefalite viral aguda transmitida por mamíferos, com letalidade de aproximadamente $100 \%$ é considerada um problema de saúde pública devido à sua alta taxa de letalidade e seus custos elevados com tratamentos, principalmente em países em desenvolvimento ${ }^{(1-2)}$. Esta zoonose é causada por vírus do gênero Lyssavirus, pertencente à família Rhabdoviridae, que se espalha pelo sistema nervoso central (SNC) e encontra-se em sobressalentes concentrações nas glândulas salivares de seu reservatório( ${ }^{(3)}$.

A raiva é por sua vez, uma zoonose que possui como reservatórios principais os cães, gatos, morcegos e carnívoros selvagens (fazem parte destes, os chacais, lobos, doninhas, raposas, coites e texugos). Sendo que os herbívoros (cavalos, bovinos, veados e outros) frequentemente são afetados pelo vírus $^{(4)}$.

Existem quatro ciclos epidemiológicos desta doença: o ciclo aéreo transmitido por morcegos; o ciclo silvestre terrestre, onde os transmissores são os animais selvagens; o ciclo rural, que engloba os animais de criação, e o ciclo urbano, que é propagado principalmente pelo cão e pelo gato. $O$ ser humano por sua vez pode ser infectado com o vírus proveniente de qualquer reservatório destes $\operatorname{ciclos}^{(5)}$.

No Brasil, entre as décadas de 1950 e 1960 os estados e municípios expandiram atividades e regulamentações voltadas ao controle desta zoonose, devido ao elevado número de casos de raiva humana propagada em sua maioria por cães. Um exemplo foi a Lei Orgânica dos Municípios publicada em 1969, no estado de São Paulo, que determinava o reconhecimento e o controle das causas determinantes e condicionantes da saúde pública por meio de ações de vigilância sanitária e epidemiológica. Para o controle da raiva foi preciso realizar atividades de imunização animal, apreensão e controle de animais errantes e campanhas de bloqueios onde havia focos nas áreas com circulação do vírus ${ }^{(5)}$.

No estado de São Paulo, ocorreu, a partir de 1994, uma considerável queda no número de casos de raiva canina, partindo de 200 casos notificados naquele ano, para somente quatro casos em 2000, com um subsequente decréscimo da raiva em humanos, transmitidas por estes animais. Em contra partida, o número de envio de amostras de animais herbívoros e de morcegos para diagnóstico laboratorial cresceu, consequentemente a frequência do vírus rábico nestes espécimes aumentou significativamente ${ }^{(\odot)}$.

Na região Noroeste do estado de São Paulo, que abrange a região de Araçatuba, foi registrada uma epidemia de raiva canina que iniciou-se em 199| no município de Andradina e estendeu-se aos municípios adjacentes numa média de $26,4 \mathrm{~km}$ por ano, afetando 10 municípios e resultante em dois casos de raiva humana nos municípios de Araçatuba e Avanhandava nos anos de 1994 e 1997 respectivamente. Os cães representaram $87,2 \%$ do total de amostras positivas, sendo registrados ainda casos em felinos, equinos, bovinos e outras espécies ${ }^{(7)}$.

O Art. $13^{\circ}$ da Lei Orgânica dos Municípios n $13.131 / 0 \mid$ do estado de São Paulo, determina que como forma de prevenção da Raiva, todo proprietário de cão e gato é responsável pela vacinação anual, ainda de acordo com a mesma, desde 1982 e 1984, a campanha contra raiva em cães e gatos, respectivamente, ocorre anualmente, e possui como objetivo a aplicação da vacina para respectiva prevenção. Esta é ofertada de forma gratuita pelo estado, e possui como meta a não circulação do vírus da raiva em caninos, felinos e consequentemente em seres humanos ${ }^{(8)}$.

Nos Estados Unidos, em 2004, foi realizado o primeiro relato, na literatura internacional, de cura da Raiva em um paciente que não havia recebido vacina. Nesta situação, o mesmo foi submetido a um tratamento baseado na utilização de antivirais e sedação profunda, denominado Protocolo de Milwaukee. Já em 2008, no Brasil, na Unidade de Terapia Intensiva do Serviço de Doenças Infecciosas do Hospital Universitário Oswaldo Cruz da Universidade de Pernambuco, em Recife-PE, foi aplicado um tratamento semelhante ao utilizado na paciente norte-americana, porém em um paciente com 15 anos de idade, mordido na ocasião por um morcego hematófago, tendo como prognóstico a eliminação viral, posteriormente tal protocolo foi denominado Protocolo de $\operatorname{Recife}^{(9)}$.

O controle da Raiva humana está associado há diversas condutas de saúde e de educação, abrangendo ações individuais e coletivas, incluindo a vacinação animal, a captura para controle de mamíferos silvestres e a profilaxia pré e pósexposição para o ser humano, além da vigilância epidemiológica efetiva e adequada. O Ministério da Saúde dispõe do Programa de Profilaxia da Raiva Humana, que atua na prevenção desta enfemidade ${ }^{(10-11)}$.

Avanços foram obtidos no controle desta zoonose, um exemplo é a redução significativa de casos de raiva humana e canina em virtude, principalmente das atividades voltadas ao reservatório canino. No Brasil, perduram áreas endêmicas para o ciclo urbano, o qual abrange reservatórios domésticos - a exemplo cães e gatos ${ }^{(12)}$. Diante do exposto, o objetivo do estudo foi avaliar o conhecimento da população usuária das Unidades Básicas de Saúde (UBSs) em relação à Raiva, no município de Birigui, estado de São Paulo.

\section{MATERIAL E MÉTODOS}

Tratou-se de uma pesquisa de natureza quantitativa e descritiva, não experimental com delineamento transversal.

\section{Descrição da área do estudo}

O município de Birigui se localiza na região noroeste do estado de São Paulo, situado a 418 metros de altitude, o município tem as seguintes coordenadas geográficas: Latitude: $21^{\circ} 17$ ' $2 l^{\prime \prime}$ Sul, Longitude: $50^{\circ} 20^{\prime} 28^{\prime \prime}$ Oeste, e possui uma população estimada de 120.692 habitantes $^{(12)}$. A população de Birigui foi escolhida como objeto de estudo por conveniência, devido à proximidade com a Universidade e à cooperação das autoridades sanitárias municipais para o desenvolvimento da pesquisa. O município desenvolve o Programa de Controle de Raiva com a Campanha Anual de Vacinação de cães e gatos, e verificação da circulação viral com remessa de material para o laboratório de Raiva da UNESP - FMVA credenciado pelo Ministério da Saúde. Dispõe de dez UBSs que fornecem atendimento de saúde pelo SUS, todas estas, localizadas em perímetro urbano.

\section{Aplicação do questionário}

Com o propósito de avaliar o conhecimento da população usuária das UBSs do município de Birigui sobre a Raiva, foi aplicado aos participantes um questionário( ${ }^{(1)}$, e adaptado do repertório sobre a zoonose raiva para este estudo.As questões deste questionário possibilitaram a avaliação do conteúdo informativo a respeito da infecção, de sua transmissão e das práticas adotadas pela população estudada, para sua prevenção. 
Os questionários foram aplicados nas dez UBSs do município de Birigui- SP de forma randomizada, para 400 participantes que, no momento da coleta de dados, encontravam-se presentes nas mesmas para atendimento de saúde.

\section{Aspectos Éticos}

O estudo foi aprovado pelo Comitê de Ética em Pesquisa envolvendo seres humanos da Faculdade de Odontologia de Araçatuba da Universidade Estadual Paulista Júlio de Mesquita Filho (FOA-UNESP), sob o protocolo $\mathrm{n}^{\circ} 3.401 .325$.

\section{Análise Estatística}

No processamento estatístico dos dados foi utilizado o programa R com a interface RStudio (Versão I.2.1335), sendo aplicado o Teste de Independência de Pearson, na análise da relação entre a variável dependente e as independentes, adotando-se o valor de $\mathrm{p}<0,05$ como nível de significância para rejeição de hipótese nula.

\section{Critérios de Inclusão e Exclusão}

Foram incluídos neste estudo moradores no município de Birigui, estado de São Paulo, usuários das UBSs maiores de 18 anos de idade e que aceitaram responder o questionário. Foram excluídas as pessoas analfabetas e aqueles que se recusaram a responder o questionário.

\section{RESULTADOS}

À análise estatística descritiva, pode-se observar na Tabela I que dos 400 entrevistados, 74,25\% (297/400) eram do sexo feminino e $25,75 \%$ (103/400) do sexo masculino, em relação à idade $44 \%$ (176/400) pertenciam a faixa etária entre 31 a 50 anos, enquanto que $34,5 \%$ (138/400) pertenciam a faixa etária de 18 a 30 anos de idade. Em relação à escolaridade $45,25 \%$ (I8I/400) participantes, relataram ter concluído o ensino médio, enquanto que $21,25 \%$ (85/400) informaram ter ensino superior completo e quando questionados sobre vínculo empregatício, 4l\% (164/400) dos entrevistados disseram que trabalhavam com carteira assinada, enquanto que $31,75 \%$ (127/400) relataram não estar trabalhando no presente momento. Com relação a possuir casa própria 68,75\% (275/400) informaram possuir, enquanto que 3I,25\% (I25/400) declaram que não. Ao associarmos a quantidade de indivíduos por residência, verificou-se que em 37,25\% (139/400) dos resultados analisados a proporção 3 indivíduos / domicílio.

Tabela I- Caracterização do perfil sociodemográfico da população usuária dos serviços prestados nas Unidades Básicas de Saúde do município de Birigui- SP, Brasil, 2019.

\begin{tabular}{|l|l|l|l|}
\hline Variável & Categoria & $\mathbf{n}$ & $\%$ \\
\hline \multirow{4}{*}{ Sexo } & Masculino & 103 & 25,75 \\
\cline { 2 - 4 } & Feminino & 297 & 74,25 \\
\hline \multirow{4}{*}{ Idade } & 18 a 30 & 138 & 34,5 \\
\cline { 2 - 4 } & 31 a 50 & 176 & 44 \\
\cline { 2 - 4 } & 51 a 65 & 54 & 13,5 \\
\cline { 2 - 4 } & 66 ou mais & 32 & 8 \\
\hline
\end{tabular}

\begin{tabular}{|c|c|c|}
\hline $\begin{array}{l}\text { Ensino } \\
\text { Fundamental } \\
\text { completo }\end{array}$ & 28 & 7 \\
\hline $\begin{array}{l}\text { Ensino } \\
\text { Fundamental } \\
\text { incompleto }\end{array}$ & 32 & 8 \\
\hline $\begin{array}{l}\text { Ensino Médio } \\
\text { completo }\end{array}$ & 181 & 45,25 \\
\hline $\begin{array}{l}\text { Ensino Médio } \\
\text { incompleto }\end{array}$ & 27 & 6,75 \\
\hline $\begin{array}{l}\text { Ensino } \\
\text { Superior } \\
\text { completo }\end{array}$ & 85 & 21,25 \\
\hline $\begin{array}{l}\text { Ensino } \\
\text { Superior } \\
\text { incompleto }\end{array}$ & 43 & 10,75 \\
\hline Nunca estudei & 4 & 1 \\
\hline $\begin{array}{l}\text { Sim, com } \\
\text { carteira } \\
\text { assinada }\end{array}$ & 164 & 41 \\
\hline $\begin{array}{l}\text { Sim, sem } \\
\text { carteira } \\
\text { assinada }\end{array}$ & 59 & 14,75 \\
\hline $\begin{array}{l}\text { Sim, em } \\
\text { regime } \\
\text { estatutário }\end{array}$ & 50 & 12,5 \\
\hline Não & 127 & 31,75 \\
\hline Sim & 275 & 68,75 \\
\hline Não & 125 & 31,25 \\
\hline I pessoa & 22 & 5,5 \\
\hline 2 pessoas & 98 & 24,5 \\
\hline 3 pessoas & 149 & 37,25 \\
\hline 4 pessoas & 96 & 24 \\
\hline $\begin{array}{l}5 \text { pessoas ou } \\
\text { mais }\end{array}$ & 35 & 8,75 \\
\hline
\end{tabular}

Fonte: Dados da pesquisa

Em relação à Tabela 2, referente ao conhecimento sobre a Raiva, a maioria dos participantes da pesquisa 97,25\% (389/400) assinalaram que já tinham ouvido falar sobre a doença, e 2,75\% ( I I/400) afirmaram não ter nenhum conhecimento e nunca terem ouvido falar sobre a enfermidade. Ressaltamos ainda que $51 \%(204 / 400)$ informaram já ter tido algum caso conhecido de Raiva, Enquanto que 49\% (196/400) dos entrevistados nunca souberam de nenhum caso da enfermidade. Dos $51 \%(204 / 400)$ que responderam ter tido conhecimento sobre algum caso de Raiva 48,53\% (99/204) informaram ter tido acesso a informação pela televisão, sendo que $38,73 \%$ (79/204) dos casos foram referentes a Raiva humana. Com relação ao nível de conhecimento da população sobre o hospedeiro transmissor da enfermidade, 67\% (268/400) dos entrevistados indicaram o cão, gato, morcego e bovino como os responsáveis pela transmissão da doença, enquanto que $16 \%(64 / 400)$ e $12,25 \%$ (49/400) associaram a transmissão apenas ao cão e ao morcego, respectivamente. Ao serem questionados sobre a forma da transmissão, observou-se que $38,5 \%$ (154/400) informaram que mesma ocorreria somente através da mordedura de um animal infectado, enquanto que $56,25 \%$ (225/400) afirmaram que a transmissão ocorria pela mordedura, arranhadura ou lambedura de um animal infectado. 
Ao serem indagados sobre a letalidade e terapêutica da doença, 88,25\% (353/400) dos entrevistados afirmaram que a Raiva era letal, enquanto que I,5\% (6/400) responderam que a enfermidade não era letal, ao mesmo tempo em que $10,25 \%$ (4l/400) assinalaram que não ter conhecimento. Com relação ao tratamento, $75,75 \%$ (303/400) alegaram que a mesma possui tratamento, enquanto que $8,25 \%$ (33/400) informaram não existir tratamento especifico e $16 \%$ (64/400) declararam não saber sobre algum tipo de tratamento especifico para a Raiva.

Tabela 2- Distribuição da população do município de BiriguiSP, Brasil de acordo com o conhecimento sobre Raiva, 2019.

\begin{tabular}{|c|c|c|c|}
\hline Variável & Categoria & $\mathbf{n}$ & $\%$ \\
\hline \multirow{2}{*}{ Ouviu falar sobre Raiva } & Sim & 389 & 97,25 \\
\hline & Não & II & 2,75 \\
\hline \multirow{2}{*}{$\begin{array}{l}\text { Conhecimento sobre } \\
\text { algum caso de Raiva } \\
\text { humana }\end{array}$} & Sim & 204 & 51 \\
\hline & Não & 196 & 49 \\
\hline \multirow{5}{*}{$\begin{array}{l}\text { Local do conhecimento } \\
\text { sobre caso de Raiva }\end{array}$} & Farmácia & 3 & 1,47 \\
\hline & Hospital & 4 & 1,96 \\
\hline & Vizinho & 19 & 9,31 \\
\hline & Ouvi falar & 79 & 38,73 \\
\hline & $\begin{array}{l}\text { Televisão/ Meios } \\
\text { digitais }\end{array}$ & 99 & 48,53 \\
\hline \multirow{7}{*}{$\begin{array}{l}\text { Animal transmissor da } \\
\text { Raiva }\end{array}$} & Somente cão & 64 & 16 \\
\hline & Somente gato & 0 & 0 \\
\hline & Somente morcego & 49 & 12,25 \\
\hline & Somente bovino & 4 & I \\
\hline & $\begin{array}{l}\text { Cão, gato, morcego e } \\
\text { Bovino }\end{array}$ & 268 & 67 \\
\hline & $\begin{array}{l}\text { Nenhuma das } \\
\text { alternativas }\end{array}$ & 4 & I \\
\hline & Não sei & 11 & 2,75 \\
\hline \multirow{6}{*}{$\begin{array}{l}\text { Maneira de transmissão } \\
\text { da Raiva }\end{array}$} & Mordedura & 154 & 38,5 \\
\hline & Arranhadura & 3 & 0,75 \\
\hline & Lambedura & 2 & 0,5 \\
\hline & $\begin{array}{l}\text { Mordedura, } \\
\text { arranhadura e } \\
\text { lambedura }\end{array}$ & 225 & 56,25 \\
\hline & $\begin{array}{l}\text { Nenhuma das } \\
\text { alternativas }\end{array}$ & 3 & 0,75 \\
\hline & Não sei & 13 & 3,25 \\
\hline \multirow{3}{*}{ Letalidade da Raiva } & Sim & 353 & 88,25 \\
\hline & Não & 6 & 1,5 \\
\hline & Não sei & 41 & 10,25 \\
\hline \multirow{3}{*}{ Tratamento da Raiva } & Sim & 303 & 75,75 \\
\hline & Não & 33 & 8,25 \\
\hline & Não sei & 64 & 16 \\
\hline
\end{tabular}

Em relação à Tabela 3 sobre a caracterização dos casos de agressões por animais no município de Birigui- SP, podemos observar que 58,25\% (233/400) dos entrevistados relataram nunca terem sofrido algum tipo de agressão por mordedura, arranhadura e ou lambedura, já 4I,75\% (167/400) informaram que em algum momento da vida sofreram agressão por animais, sendo que $62,87 \%$ (105/167) informaram terem sido agredidos por cães, I7,96\% (30/I67) por gatos e I,2\% (2/167) por morcegos. Quando questionados sobre como trataram da agressão 43,11\% (72/167) dos participantes informaram que lavaram o local da lesão com água e sabão, enquanto $14,37 \%$ (24/167) afirmaram que não foi realizado nenhum procedimento no local da agressão, e 67,66\% (1/3/167) informaram ter buscado ajuda médica enquanto, $32,34 \%$ (54/167) não buscaram socorro médico. Dos que buscaram ajuda médica, $57,52 \%$ (65/II3) declararam ter procurado o Pronto Socorro, enquanto $38,05 \%$ (43/II3) procuraram a Unidade Básica de Saúde.

Tabela 3- Caracterização dos casos de agressões por animais no município de Birigui- SP, Brasil, 2019.

\begin{tabular}{|c|c|c|c|}
\hline Variável & Categoria & $\mathbf{n}$ & $\%$ \\
\hline \multirow[t]{2}{*}{ Agressão animal } & Sim & 167 & 41,75 \\
\hline & Não & 233 & 58,25 \\
\hline \multirow{6}{*}{$\begin{array}{l}\text { Espécie responsável } \\
\text { pela agressão }\end{array}$} & Gato & 30 & 17,96 \\
\hline & Cão & 105 & 62,87 \\
\hline & Cão e gato & 26 & 15,57 \\
\hline & Morcego & 2 & 1,2 \\
\hline & Bovino & 0 & 0 \\
\hline & Outro & 4 & 2,4 \\
\hline \multirow{4}{*}{$\begin{array}{l}\text { Cuidados com o } \\
\text { ferimento }\end{array}$} & Não fiz nada & 24 & 14,37 \\
\hline & Passei álcool & 19 & 11,38 \\
\hline & Lavei com água e sabão & 72 & 43,11 \\
\hline & $\begin{array}{l}\text { Passei álcool e lavei } \\
\text { com água e sabão }\end{array}$ & 52 & 31,14 \\
\hline \multirow{2}{*}{$\begin{array}{l}\text { Recorreu aos } \\
\text { serviços de saúde }\end{array}$} & Sim & 113 & 67,66 \\
\hline & Não & 54 & 32,34 \\
\hline \multirow{3}{*}{$\begin{array}{l}\text { Serviço de saúde } \\
\text { requisitado pelo } \\
\text { participante }\end{array}$} & Farmácia & 5 & 4,43 \\
\hline & Pronto Socorro & 65 & 57,52 \\
\hline & $\begin{array}{l}\text { Unidade Básica de } \\
\text { Saúde }\end{array}$ & 43 & 38,05 \\
\hline
\end{tabular}

$\mathrm{Na}$ tabela 4 podemos observar que 75,25\% (30I/400) dos entrevistados responderam ter animal de estimação em casa, enquanto que $24,75 \%$ (99/400) declararam não possuir nenhum animal de estimação no domicílio, dos $75,25 \%$ que possuíam animais de estimação 43,19\% (I30/30I) dos participantes afirmaram ter somente um animal domiciliado, enquanto que $26,58 \%$ (80/30I) afirmaram possuir dois animais. Com relação à caracterização dos animais de estimação 65,45\% (I97/30I) dos entrevistados declararam possuir cão, enquanto que 10,63\% (55/30I), informaram possuir cão e gato no domicílio. Com relação à imunoprofilaxia antirrábica dos animais, 85,05\% (256/30I) da população informou já ter realizado esquema vacinal, enquanto $14,95 \%$ (45/30I) declararam que nunca o fizeram. Desses $85,05 \%$ que declararam ter realizado a vacinação antirrábica em seu pet, I,02\% (233/256) relataram faze-la anualmente, enquanto $73 \%$ (7/256) expuseram que somente realizara a vacinação, quando os animais ficaram doente e foram levado ao veterinário e 6,25\% (16/256) referiram não saber a periodicidade do ciclo vacinal.

Tabela 4 - Distribuição do número de animais e vacinação dos mesmos no município de Birigui- SP, Brasil, 2019.

\begin{tabular}{|l|l|l|l|}
\hline Variável & Categoria & $\mathbf{n}$ & $\%$ \\
\hline \multirow{2}{*}{$\begin{array}{l}\text { Presença de animal de } \\
\text { estimação no domicílio }\end{array}$} & Sim & 301 & 75,25 \\
\cline { 2 - 4 } & Não & 99 & 24,75 \\
\hline
\end{tabular}




\begin{tabular}{|c|c|c|c|}
\hline \multirow{6}{*}{$\begin{array}{l}\text { Número de animais no } \\
\text { domicílio }\end{array}$} & I & 130 & 43,19 \\
\hline & 2 & 80 & 26,58 \\
\hline & 3 & 54 & 17,94 \\
\hline & 4 & 20 & 6,64 \\
\hline & 5 & 7 & 2,33 \\
\hline & 6 ou mais & 10 & 3,32 \\
\hline \multirow{5}{*}{$\begin{array}{l}\text { Espécie do animal de } \\
\text { estimação }\end{array}$} & Cão & 197 & 65,45 \\
\hline & Gato & 32 & 10,63 \\
\hline & Cão e gato & 55 & 18,27 \\
\hline & Pássaro & 7 & 2,33 \\
\hline & Outros & 10 & 3,32 \\
\hline \multirow{2}{*}{$\begin{array}{l}\text { Realização de vacinação } \\
\text { antirrábica no animal }\end{array}$} & Sim & 256 & 85,05 \\
\hline & Não & 45 & 14,95 \\
\hline \multirow{3}{*}{$\begin{array}{l}\text { Periodicidade de vacinação } \\
\text { do animal }\end{array}$} & Não sei & 16 & 6,25 \\
\hline & $\begin{array}{l}\text { Somente quando } \\
\text { fica doente }\end{array}$ & 7 & 2,73 \\
\hline & Todos os anos & 233 & 91,02 \\
\hline
\end{tabular}

$\mathrm{Na}$ tabela 5 encontramos a associação entre as variáveis dependentes $\mathrm{e}$ as independentes do estudo testadas, onde podemos observar os resultados estatisticamente significativos, os valores mais expressivos foram encontrados na associação da variável dependente idade com a variável independente qual animal transmite a Raiva onde encontramos o p-valor 0,0000234 seguida da variável dependente escolaridade associada à variável independente se já ouviu falar sobre a Raiva onde o p-valor foi de 0,0008246 .

Tabela 5 - Correlação entre as variáveis dependentes e independentes utilizando $\circ$ Teste de $X^{2}$ no município de Birigui- SP, Brasil, 2019.

\begin{tabular}{|l|l|l|}
\hline $\begin{array}{l}\text { Variáveis } \\
\text { independentes }\end{array}$ & Variáveis dependentes & P-valor \\
\hline Sexo & $\begin{array}{l}\text { Animal transmissor da } \\
\text { Raiva }\end{array}$ & \\
\hline Feminino & $\begin{array}{l}\text { Práticas de vacinação } \\
\text { adequadas }\end{array}$ & 0,00243 \\
\hline Feminino & & 0,04675 \\
\hline Escolaridade & Ouviu falar sobre a Raiva & \\
\hline Ensino Médio Completo & & 0,0008246 \\
\hline Ensino Médio Completo & Tratamento & \\
\hline & $\begin{array}{l}\text { Práticas de vacinação } \\
\text { adequadas }\end{array}$ & 0,00137 \\
\hline Ensino Médio Completo & & 0,04675 \\
\hline Idade & $\begin{array}{l}\text { Animal transmissor da } \\
\text { Raiva }\end{array}$ & \\
\hline 18 a 30 anos & & 0,0000234 \\
\hline & Ouviu falar sobre a Raiva & \\
\hline 18 a 30 anos & & 0,00157 \\
\hline Agressão por animais & $\begin{array}{l}\text { Animal responsável pela } \\
\text { agressão }\end{array}$ & \\
\hline Cão & & 0,02562 \\
\hline
\end{tabular}

\section{DISCUSSÃO}

Este estudo teve como objetivo compreender o conhecimento e práticas da Raiva e seu controle entre a população atendida nos serviços primários de saúde na cidade de Birigui, São Paulo, Brasil. Para nosso entendimento, este é o primeiro estudo sobre Raiva realizado entre a comunidade da cidade de Birigui- SP, Brasil. Esperamos que as nossas descobertas guiem as autoridades locais para uma tomada de decisão com o intuito de melhorar a prevenção e o controle da raiva em cães, gatos, morcegos e em seres humanos por meio de um programa educacional direcionado à comunidade.

Caracterizando o perfil da população estudada, verificouse que a maioria dos entrevistados que procuram socorro junto ao serviço público de saúde constitui-se de mulheres, semelhantemente aos achados de ${ }^{(13)}$. Tal fato justifica-se pela relutância apresentada pelos homens em procurar ajuda junto aos serviços de saúde, corroborando com outros trabalhos já desenvolvidos que abordaram o mesmo escopo ${ }^{(14)}$

A cidade de Birigui é referência na América Latina em relação à indústria do calçado infantil tendo o maior polo trabalhista no setor ${ }^{(15)}$, portanto justifica-se que a maioria dos entrevistados, pertenciam a faixa etária entre 31 e 50 anos, representando a classe economicamente ativa da população, semelhante aos dados apontados por ${ }^{(13)}$.

A percepção de tal população sobre conhecimentos que permeiam o tema em questão demonstrou ser bem mais informada que a população mais jovem da sociedade, sugerindo, portanto, que $\circ$ assunto deve-se ser debatido nos ambientes escolares, principalmente no ensino Médio e Fundamental. Uma vez que o grau de escolaridade dos envolvidos revelou que a grande maioria que possuíam ensino médio completo, apresentaram rico conhecimento sobre a enfermidade, a existência de práticas preventivas e de esquema imunoprofilático, além de adotar tais medidas, ainda afirmaram fazer uso dos serviços públicos de saúde em caso de agressões e/ou contato com animal suspeito, semelhante aos resultados encontrados por ${ }^{(16)}$ em Kigali, na Ruanda, onde ao avaliar o conhecimento, atitudes e práticas de tutores de cachorros sobre a Raiva encontrou nível elevado de conhecimento na população que possuía grau de escolaridade primário, secundário e terciário quando comparado aos que não possuíam escolaridade e por ${ }^{(17)}$ que no seu estudo realizado na India verificou que os trabalhadores mais experientes e com melhor escolaridade possuíam conhecimento elevado sobre a raiva quando comparado aos demais.

O estudo ainda revelou a importância da informação veiculada pelos meios de comunicação via mídias televisão e digital, sendo que ambas as formas foram apontadas como ferramentas de busca de informação da população mais jovem do estudo. Os resultados demonstram a extrema importância da adoção de políticas públicas de educação continuada voltada para 0 ambiente escolar descentralizando $o$ assunto dos cursos de graduação e pós-graduação, visto que há muita desinformação sobre o tema e diante da gravidade da doença e da existência de práticas preventivas e de ações significativas que possam efetivamente coibir e mitigar o desenvolvimento e/ou o agravo da enfermidade, é urgente que tal temática seja amplamente discutida pela sociedade.

Atualmente, segundo o Ministério, contamos com medidas preventivas que devem ser adotadas por todos os municípios como: pós-exposição para seres humanos após contato ou agressões, vacinação anualmente para cães e gatos, captura de cães errantes e a educação em saúde da população em geral sobre a epidemiologia, prevenção e práticas pós-exposição. Apesar de tais medidas terem como meta o aumento da 
conscientização sobre a Raiva, elas também são fundamentais para que mais munícipes aprendam sobre a doença, ainda que seus conhecimentos sobre vários aspectos da enfermidade permaneçam incompletos $^{(11)}$.

$A$ vacinação é uma estratégia consolidada pelo Ministério da Saúde como medida de prevenção contra esta zoonose, consecutivamente garantindo a saúde única, e o bem-estar do animal, para que os protocolos sejam executados de maneira apropriada, é fundamental que os tutores dos animais tenham ciência sobre os esquemas corretos, de acordo com as recomendações dos médicos veterinários, e estabelecidos pelo Ministério da Saúde ${ }^{(18)}$, o mesmo tem como embasamento no estilo de vida do animal e o risco de exposição à doença salvo exigências internacionais por manuais que devem ser seguidos $^{(19)}$.

Neste contexto, se faz de extrema importância à continuidade da educação em saúde por profissionais capacitados, a inclusão de temas sobre a Raiva e demais zoonoses junto ao ensino médio e fundamental, a fomentação de campanhas educativas do governo exibidas pelas mídias digitais e televisão e a continuidade da campanha de vacinação antirrábica anual.

\section{CONCLUSÃO}

A população demonstrou conhecimento elevado sobre a Raiva, visto que em sua maior parte os entrevistados souberam quais eram os fatores causadores da doença como a transmissão, letalidade, terapêutica e medidas de prevenção, além de já terem ouvido falar sobre a zoonose em sua maior parte por meios digitais ou trocas de informações entre os indivíduos.

Por outro lado, observamos que, parte dos participantes não atribuíram corretamente alguns dos reservatórios do vírus, e afirmaram que a zoonose tem cura, colocações que são preocupantes, uma vez que o gato e morcego vêm mudando o ciclo epidemiológico da doença, e o prognóstico da recuperação clínica dos pacientes acometidos pelo vírus não é totalmente satisfatório.

Portanto a educação em saúde deve ser realizada de forma contínua para que todos os munícipes possuam conhecimento suficiente da zoonose nas vertentes de transmissão, terapêutica e letalidade da Raiva.

\section{AGRADECIMENTOS}

Agradeço à Coordenação de Aperfeiçoamento de Pessoal de Nível Superior - CAPES pelo suporte financeiro e às autoridades sanitárias do município de Birigui autorizaram a realização desta pesquisa.

\section{REFERÊNCIAS BIBLIOGRÁFICAS}

1. Brasil. Ministério da Saúde. Secretaria de Vigilância em Saúde. Guia de Vigilância Epidemiológica. $6^{\mathrm{a}}$ ed. Brasília: MS; 2005 [acesso em 21 dez 2019]. Disponível em: http://bvsms.saude.gov.br/bvs/publicacoes/Guia_Vig_ Epid_novo2.pdf

2. Warrell MJ, Warrell DA. Rabies and other lyssavirus diseases. The Lancet 2004;363(94/3):959-969.

3. Batista HBCR, Schmidt E, Caldas E, Massunaga P, Teixeira TF, Schaefer R, et al. Caracterização de amostras do vírus da raiva, isoladas nas regiões Norte e Centro-Oeste do Brasil, com anticorpos monoclonais antilissavírus.Arq Bras Med Vet e Zootec.
2008;60(I):260-2.

4. Babboni SD, Modolo JR. Rabies: origin, importance and historical aspects. Raiva origem, importancia e Asp Hist [Internet]. 2011 [acesso em 21 dez 2019];। 3(Special):349-56. Disponível em: http://revista. unopar.br/biologicaesaude/revistaBiologicas/list\#!

5. Brasil. Ministério da Saúde. Secretaria de Vigilância em Saúde. Guia de vigilância epidemiológica. 7a ed. Brasília: Ministério da Saúde; 2009 [acesso em 21 dez 2019]. Caderno 13: Raiva. (Série A. Normas e Manuais Técnicos). Disponível em: http://bvsms.saude.gov.br/ bvs/publicacoes/guia_vigilancia_epidemiologica_7ed. pdf

6. Takaoka NY. Alteração no perfil epidemiológico da raiva no estado de São Paulo. In: Resumos do Seminário Internacional de Raiva, São Paulo p.23-24, 2000.

7. Queiroz LH, de Carvalho C, Buso DS, Ferrari CIDL, Pedro WA. [Epidemiological profile of rabies in the northwestern region of São Paulo State, from 1993 to 2007]. Rev Soc Bras Med Trop [Internet]. 2009 [acesso em 21 dez 2019];42(I):9-14. Disponível em: http:// www.ncbi.nlm.nih.gov/pubmed/I9287928

8. São Paulo, Lei Orgânica dos Municípios No I3.|3|, de I 8 de maio de 200 I.Prefeitura do Estado de São Paulo, São Paulo, SP, maio de 200 I.

9. Wada MY, Rocha SM, Maia-Elkhoury ANS. Situação da Raiva no Brasil, 2000 a 2009. Epidemiol e Serviços Saúde [Internet]. 201 I [acesso em 2I dez 2019];20(4):509-I8. Disponível em: http://scielo.iec. pa.gov.br/scielo.php?script=sci_arttext\&pid=S1679. 497420 I I0004000 I 0\&Ing=en\&nrm=iso\&tlng=en

10. Reichmann MLAB, Pinto HBF, Arantes MB, Dos Santos $M B$, Viaro O, Nunes VFP, Educação e promoção da saúde no programa de controle da raiva. São Paulo: Instituto Pasteur, 2000 [acesso em 21 dez 2019]. 30p. (Manual Técnico, v. 5). Disponível em: http:// www.saude.sp.gov.br/resources/instituto-pasteur/pdf/ manuais/manual_05.pdf

11. Brasil. Ministério da Saúde. Fundação Nacional de Saúde. Relatório Final de Avaliação do Programa Nacional de Controle da Raiva no Brasil: 22 de abril a 3 de maio 2002. Brasília: Organização Pan-Americana da Saúde; Organização Mundial da Saúde; Ministério da Saúde; 2002 [acesso em 21 dez 2019]. Disponível em: http://87.191.71.192/expediente/4539/mir/I3858/ anexo/492284

12. IBGE, Diretoria de Pesquisas, Coordenação de População e Indicadores Sociais, Estimativas da população residente com data de referência lo de julho de 2017.

13. Tomé R, Langoni H, Peruca L, Babboni S. Avaliação do Conhecimento Sobre Algumas Zoonoses com Proprietários de Cães da Área Urbana do Município de Botucatu-SP.J Heal Sci. 2010;12(3):67-74.

14. Tomé R, Langoni H, Peruca L, Babboni S. Avaliação do Conhecimento Sobre Algumas Zoonoses com Proprietários de Cães da Área Urbana do Município de Botucatu-SP.J Heal Sci. 20 I0; I2(3):67-74.

15. Rizzo MR.A Evolução da Indústria Calçadista de Birigui. Birigui: Boreal, 2005.

16. Ntampaka P, Nyaga PN, Niragire F, Gathumbi JK, Tukei M. Knowledge, attitudes and practices regarding 
rabies and its control among dog owners in Kigali city, Rwanda. PLoS One. 2019; I4(8):e0210044.

17. Tiwari HK, Vanak AT, O'Dea M, Robertson ID. Knowledge, attitudes and practices towards dog-bite related rabies in para-medical staff at rural primary health centres in Baramati, western India. PLoS One. 20 18; I 3(I I):e0207025.

18. BRASIL. Ministério da Saúde. Secretaria de Vigilância em Saúde. Departamento de Vigilância Epidemiológica. Normas Técnicas de Profilaxia da Raiva Humana/ Ministério da Saúde, Secretaria de Vigilância em Saúde, Departamento de Vigilância Epidemiológica - Brasília: Ministério da Saúde, 20II.60p.: il.
19. American Animal Hospital Association (AAHA). Canine vaccine guidelines. Journal of the American Animal Hospital Association. $201 \mathrm{I}$ [acesso em: 25 set. 2019];47(5): I-42.Disponível em:<https://www.aahanet. org/PublicDocuments/ CanineVaccineGuidelines.pdf>

Recebido: 2019-11-18

Aceito: $2019-12-24$ 